\title{
Proceeding
}

Supplementary Issue: Spring Conferences of Sports Science. 15th Convention and Workshop of the International Network of Sport and Health Science, 5-8 June 2019. University of Las Palmas de Gran Canaria, Las Palmas de Gran Canaria, Spain.

\section{Long life learning on physical activity}

\author{
MATTIA PISANO 1 , ILARIA VISCIONE ${ }^{1}$, FRANCESCO PELUSO CASSESE², GAETANO ALTAVILLA ${ }^{3}$ \\ ${ }^{1}$ University of Salerno, Italy \\ 2University Niccolò Cusano of Rome, Italy \\ 3 University of Split, Croatia
}

\begin{abstract}
The University for elderly people was born as a cultural and social service and is widely used. They are part of post-secondary training and in some cases the educational offer is of a good standard and satisfaction. The growing demand for well-being linked to physical activity and healthy lifestyles also requires a study on the activities of other training agencies other than universities. The aim of the study is to carry out the most significant qualitative and quantitative data in Italy and abroad on physical activity. The method is the survey investigation of data with the tools of the questionnaires and the interviews. Through the analysis of the organization structure, the courses, the contents and education scope are possible to identify the aggregate and disaggregated data in 4 categories: theoretical courses, physical activities path, laboratories and other activities to carry out the quantity data of physical activities compared to other categories. The education courses are 8207 of which: 4636 are theoretical courses, 1227 physical activities, 2344 laboratories. In addition to the quantity, it carries out the homogeneous localization on the national and international territory and the similar organization and management. It shows a consolidated culture of the phenomenon that should also be of interest to the public Institution, including the Ministry of Education and the individual universities. In conclusion, it is advisable to investigate furtherly to obtain more useful data also in relation to the progressive increase in life expectancy and the social costs of it. Keywords: Life expectancy; Laboratory; Wellness.
\end{abstract}

\section{Cite this article as:}

Pisano, M., Viscione, I., Cassese, F.P., \& Altavilla, G. (2019). Long life learning on physical activity. Journal of Human Sport and Exercise, 14(4proc), S691-S697. doi:https://doi.org/10.14198/ihse.2019.14.Proc4.29

Corresponding author. University of Split, Croatia.

E-mail: gaetano.altavilla @libero.it

Supplementary Issue: Spring Conferences of Sports Science. 15th Convention and Workshop of the International Network of Sport and Health Science, 5-8 June 2019. University of Las Palmas de Gran Canaria, Las Palmas de Gran Canaria, Spain. JOURNAL OF HUMAN SPORT \& EXERCISE ISSN 1988-5202

(c) Faculty of Education. University of Alicante

doi:10.14198/jhse.2019.14.Proc4.29 


\section{INTRODUCTION}

With the increase in life expectancy and the average age of population, the number of seniors today has grown over time and for this reason he felt the need to promote active aging (Altavilla et al, 2018, Tiziana et al, 2018. Gaetano 2017, Altavilla et al, 2015) and their performance (D'Isanto et al, 2019). In this regard, in 1973 at Toulouse, a French town, it was founded the first University of The Third Age (U3A) (Swindell, Thompson, 1995) whose program will become a model for future U3A worldwide. The University of The Third Age are the public institutions mainly aimed at adults and the elderly, with the aim of promoting, through numerous activities and courses, culture among citizens, encouraging the inclusion of the elderly in social and cultural life. The U3A do not follow a universal model agreed but while presenting different organizationaleducational types which vary from country to country, all are based on two main models: the French and the British.

- $\quad$ The French model is the first to have developed and has been used by most European countries. It is based purely on managing and university planning; in which the proposed activities are details of their University of origin. Consequently, the lessons take place in academic settings with qualified teachers. The elderly tends to play a passive role.

- The British model was born eight years later than French one, mainly adopted by all countries that speak English; It differs considerably. This model is not anchored to traditional universities but is rather more focused on knowledge sharing the courses present a free program, are totally independent both from a management point of view of financing. The idea is not to formalize the education of candidates through traditional college courses, but to promote a two-way teaching as applicants come from "background" of different experiences. Classes are held with experienced seniors who want to become involved by providing their knowledge with others. The elderly tends to play a much more active role.

Starting from this little example for the Universities of the Third Age, this work examines the Italian national system and internationally, providing an idea of how these structures are organized and the type of activities. In the university exercise and sport sciences degree is wide and the course are much developed (D'Elia, 2019,D'Elia et al, 2018, D'Isanto, 2019, 2016, Raiola et al, 2018, Sanseviero et al, 2019). The purpose of the study is to provide qualitative and quantitative most important in Italy and abroad on physical activity and sports sciences (Cassese, Raiola, 2017, Ceciliani, 2019, Ceciliani et al, 2005, Raiola 2017, 2015, 2013, Raiola, Di Tore, 2017, Raiola, 2013) . Through the analysis of the organization of the courses, the training objectives and the physical activity were identified four categories regarding physical activities (Tore et al 2018, Di Tore et al, 2018) : theoretical courses, motor activities (Valentini et al, 2018ab), workshops and other activities to pull out the data related to the amount of practice (motor activities and laboratory) compared to other categories.

\section{MATERIAL AND METHODS}

Universities in Italy are united in national associations such as: FEDERUNI (Italian Federation of University of The Third Age), UNITRE (National Association of Universities of the Three Age) and AUPTEL (Association of People's Universities of the Third Age and free of age); What they are tasked to unify and represent these structures abroad. The research carried out in the Italian university aims to provide public hearing on the Third Age University overall national territory. First, thanks to the vision of the national federation registers (FEDERUNI) and association (UNITRE) have been identified in all the Universities of the Third Age in the national territory. It must be said that not all actually existing universities are affiliated to one of the 
associations. Some larger sites include, manage and control the surrounding offices throughout the country, in these cases is affiliated only the main office. Therefore, the data may be underestimated, since it is difficult to analyse every little reality of the Italian territory. The identified locations and taken into consideration for this search are 410; to facilitate the collection they are grouped by region.

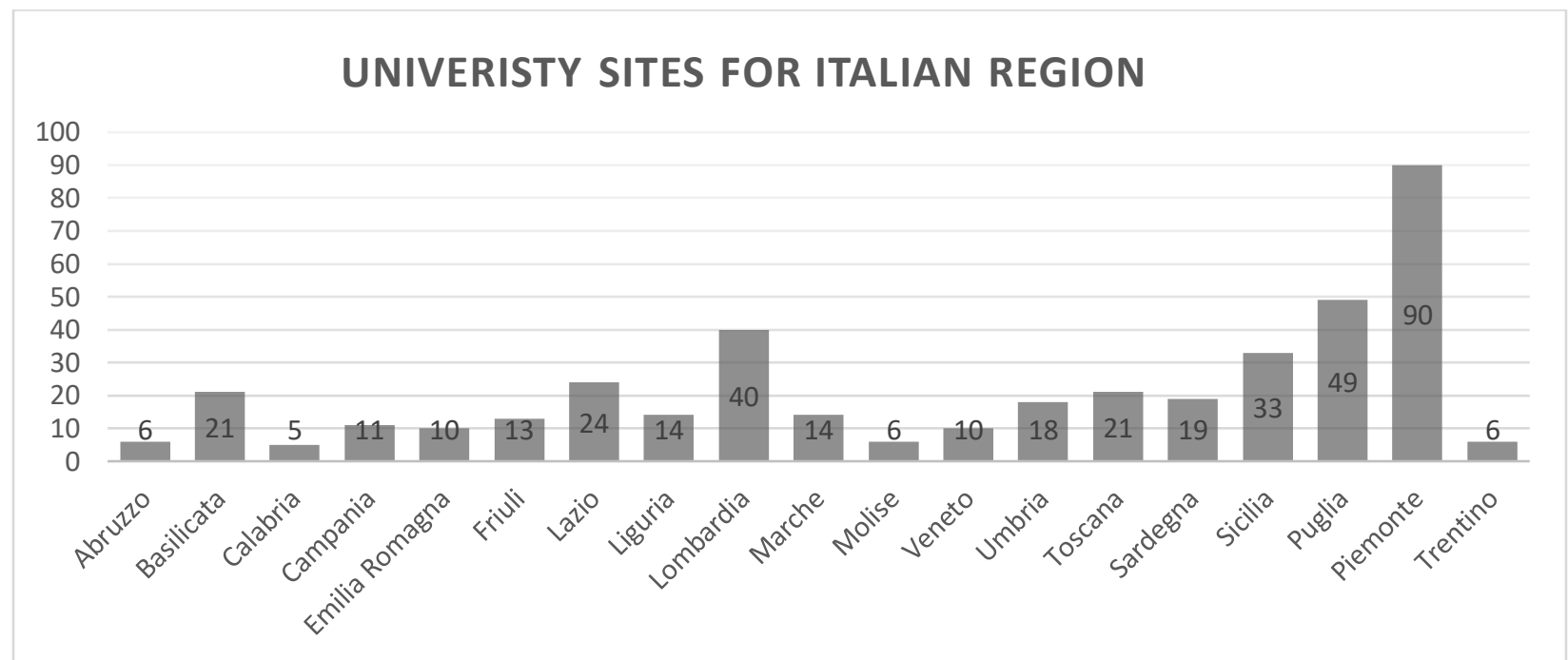

Figure 1. Presence of university sites by region. Based on the structures registered to the federation or association of Italian of the Third Age University

For each location identified were taken contact information such as email address or telephone number of the machine or the controller and the related web sites if any. The universities were contacted all via e-mail.

Not all universities have responded contact, in fact, the data relate to 340 structures since 70 locations have not given any response, and there were no other contact mode or delivery of the necessary survey data.

The information required for this article was related to the type and structure of courses. The proposed activities at each university were listed and then divided into four main categories: theoretical courses, motor activities, workshops and other activities. The division of courses by category was based on the type of material, the teaching methods, the training objectives and the place where it carries out the lesson.

\section{RESULTS}

The results confirmed that most of the activities of the elderly are mainly theoretical. In fact, as can be seen in the graph below (Figure 2) activities relating to the theory are $56 \%$, more than half of disciplines proposals are aimed at structuring knowledge base or advanced that are part of one of the four objectives of the University Third Age. The laboratory proposals instead represent $29 \%$, while the motor practice corresponds only to $15 \%$. If arises a theory based on subdivision and practice (laboratories and motor activity), the distance between the parts is reduced $44 \%$ by becoming a practical and always a $56 \%$ theoretical. The number of total courses is 8207 :

- 4636 relate to theoretical courses;

- 1227 motor activities within institutions; 
- 2344 is the laboratory activities

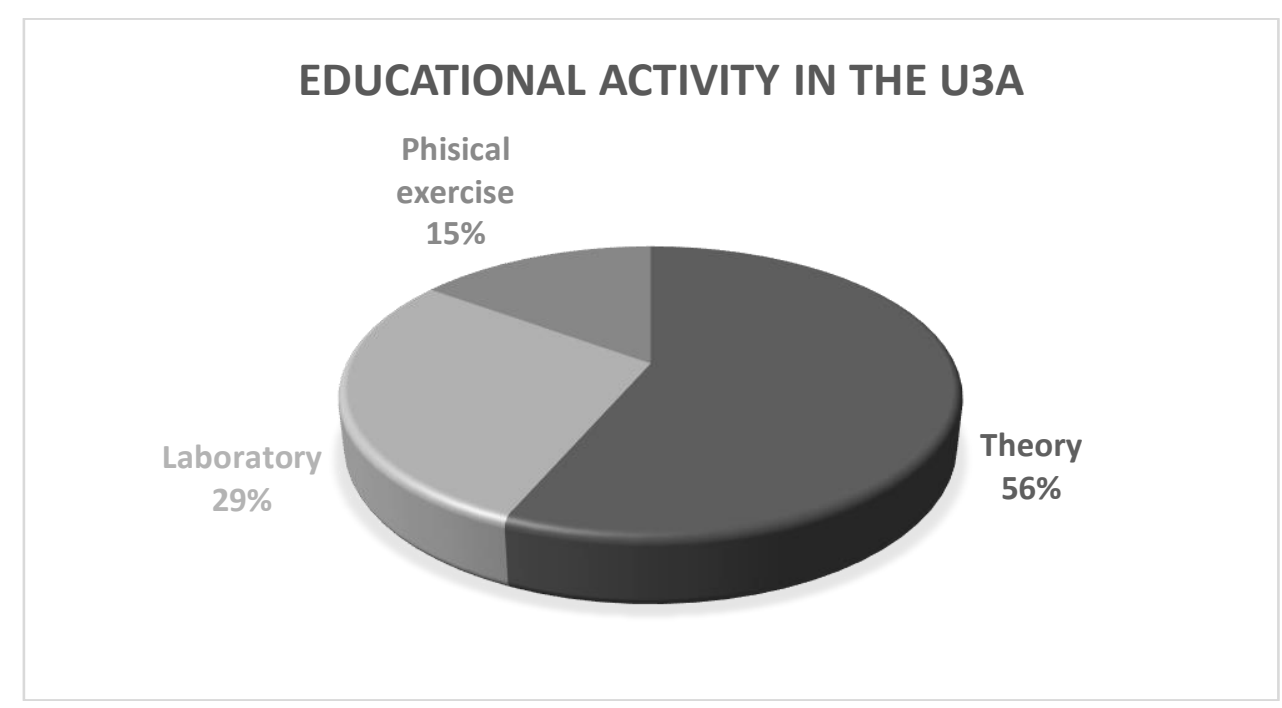

Figure 2. Relationship between educational activities: theory, laboratory and physical exercise.

For the international survey five countries were chosen: France, USA, Germany, Australia and Japan who can best represent the different types and university methods. Hence according to the availability of information on the search engines you have selected some universities in each country. The purpose of the analysis is to see and evaluate the proposed university internationally. At the end of three locations they have been identified for each country. In the graph below, you can see a correspondence between the countries that use the British model (the United States, Australia and Japan) and those who use the traditional French method (Germany and France). In fact, countries with minimum gaps between the various activities are those that are based on the British model, while the other presentiment of a much more dominant theoretical framework.

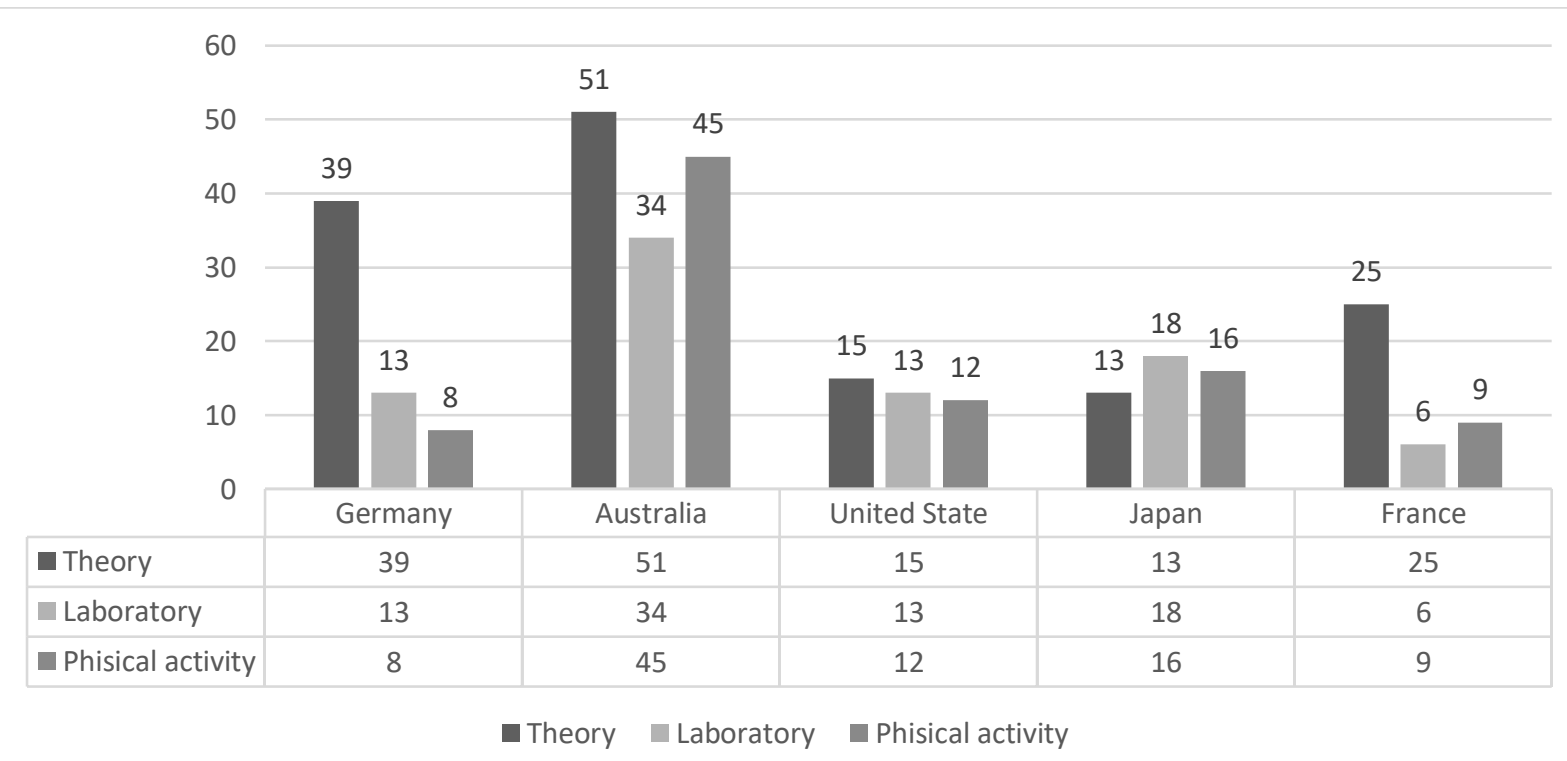

Figure 1. Relationship between international universities of the third age: France, Germany, USA, Japan and Australia, compared to the number of courses offered. 
The most present laboratory activities were: painting, computer, sewing. Often these institutions make available to their members a broad outline of cultural activities such as conferences, meetings, guided tours and educational trips in Italy or abroad to complete most of the educational experience.

Table 1. First activities

\begin{tabular}{ll} 
Painting & $58.8 \%$ \\
Computer technology & $58.5 \%$ \\
Sewing & $48.2 \%$ \\
Theatre Workshop & $41.5 \%$ \\
Choral & $41.2 \%$ \\
Kitchen & $35.3 \%$ \\
Photography & $34.1 \%$ \\
Drawing & $32.4 \%$ \\
Burraco (cards game) & $29.7 \%$ \\
\hline
\end{tabular}

Practical activities vary as all other materials from University to University but almost all include: dance, yoga and gymnastics. During the research it was found that the most present physical activities are also those most suited to the lifestyle of an elderly, as reflected in the table below:

Table 2. Second activities

\begin{tabular}{lc} 
Group dance & $60.6 \%$ \\
Yoga & $43.2 \%$ \\
soft gymnastics & $25.9 \%$ \\
Dance & $20.9 \%$ \\
Memory training & $17.6 \%$ \\
Chess & $13.2 \%$ \\
Pilates & $12.1 \%$ \\
Walk & $10.0 \%$ \\
\hline
\end{tabular}

The benefits of these activities are numerous and incontestable. Physical activity especially in the elderly becomes essential for maintaining the autonomy, self-sufficiency and in the slowing of the physiological decline. Nevertheless, these cover only $15 \%$ of the total, and in most cases analysed, are practiced once a week. As for the British model the proposed activities are much more balanced approximately $49 \%$ on a percentage basis (as far as those analysed), but the activities that take place within them are always the same.

\section{DISCUSSION}

The University of the Third Age today represent a dynamic of the adult education movement, flexible and affordable that meets the wants and needs of a number that will always be on the rise. In many countries where there are national organizations, these are purely voluntary role and do not promote proper single direction providing a relationship between practical and theoretical activities adapted to the needs of the elderly. Given that one of the greatest strengths of the university movement is their basic autonomy, individual universities must take the lead in promoting and benefiting the presence of practical activities.

The motor activity plays a marginal role compared to the other proposals; but that does not mean that the theory should be completely excluded or eliminated, since one of the four founding principles relating to the 
promotion of culture. The U3A allow, through numerous activities and programs, to promote and spread the culture among the citizens, encouraging the inclusion of the elderly in social and cultural life.

The courses that you can attend are numerous and very diverse, ranging from matters literary, scientific and artistic. In addition to these you can attend courses on: foreign languages (English, French, German and Spanish), and computing power. These activities provide the knowledge that I allow the elderly to live more peaceful and independent. The University of The Third Age they are important because they allow all 'elder: to feel part of society, to make available their experience and knowledge, to keep active both cognitively and physically.

\section{CONCLUSIONS}

In this paper we have seen how, in the University of The Third Age, although there is awareness of the importance of physical activity in the elderly, the number of operating this type is much lower in relation to the amount of the courses that have a merely theoretical. This, however, applies in universities based on the French model, but something very different about the British model; where there is a greater and more equitable balance. Today the College Third Age are considered state of the art institution for the elderly, a showcase of their work and their areas of interest, thus always play a more important and significant role for society. These must then point to the formation of an active senior in complete physical, mental and social. The best way to do that is to do more physical activity within schools and reduce the theoretical courses thus increasing the number of activities relating to fundamental motor practice for the preservation of autonomy and physical and psychological self-sufficiency.

\section{REFERENCES}

Altavilla, G., D'Elia, F., Raiola, G. (2018) A brief review of the effects of physical activity in subjects with cardiovascular disease: An interpretative key, Sport Mont, 16 (3), pp. 103-106.

Altavilla, G., Furino, F., Marika, D.P., Raiola, G. (2015) Physical skills, sport learning and socio-affective education, Sport Science, 8, pp. 44-46.

Cassese, F.P., Raiola, G. (2017) The importance of sport in disability management, Sport Science, 10, pp. 7-11.

Ceciliani, A. (2018) From the embodied cognition to the embodied education in the physical and sports sciences, Encyclopaideia, 22 (51), pp. 11-24.

Ceciliani, A., Di Carlo, M., Tentoni, C. (2005) Mental process learning Medicina dello Sport, 58 (1), pp. 43-52.

D'Elia, F. (2019). The training of physical education teacher in primary school. Journal of Human Sport and Exercise, 14(1 proc), S100-S104. https://doi.org/10.14198/jhse.2019.14.Proc1.12

D'Elia, F., Mazzeo, F., Raiola, G. (2018) The core curriculum in the university training of the teacher of physical education in Italy, Journal of Human Sport and Exercise, 13, pp. S413-S420. https://doi.org/10.14198/ihse.2018.13.proc2.25

D'Isanto, T., D'Elia, F., Raiola, G., Altavilla, G. (2019) Assessment of sport performance: Theoretical aspects and practical indications, Sport Mont, 17 (1), pp. 79-82.

Di Tore, A.P., Raiola, G., D'Isanto, T. (2018) Situation awareness in sports science: Beyond the cognitive paradigm [Situacijska svijest u sportskoj nauci: Van kognitivne paradigme]Sport Science, 11 (1), pp. 44-48. 
D'isanto, T. (2019) Physical and sport education between Italian academic system and European Research Council structure panel, Journal of Human Sport and Exercise, 14, pp. S66-S76. https://doi.org/10.14198/ihse.2019.14.proc1.08

D'Isanto, T. (2016) Pedagogical value of the body and physical activity in childhood, Sport Sci-ence, 9, pp. 13-18.

Gaetano, A. (2016) Relationship between physical inactivity and effects on individual health status, Journal of Physical Education and Sport, 16, pp. 1069-1074.

Raiola, G., D'elia, F., Altavilla, G. (2018) Physical activity and sports sciences between European Research Council and academic disciplines in Italy, Journal of Human Sport and Exercise, 13, pp. S283-S295. https://doi.org/10.14198/jhse.2018.13.proc2.13

Raiola, G. (2015) Inclusion in sport dance and self perception Sport Science, 8, pp. 99-102.

Raiola, G. (2013) Body knowledge and motor skills, Knowledge Cultures, 1 (6), pp. 64-72.

Raiola, G. (2017) Motor learning and teaching method, Journal of Physical Education and Sport, 17, art. no. 236, pp. 2239-2243.

Raiola, G., Di Tore, P.A. (2017) Motor learning in sports science: Different theoretical frameworks for different teaching methods, Sport Science, 10, pp. 50-56.

Sanseviero, I., Cassese, F.P., Fonzo, E., Altavilla, G., D'elia, F. (2019) Study on the master's degree in sciences of sports evaluation and sport for disabled at the University of Salerno, Italy. Journal of

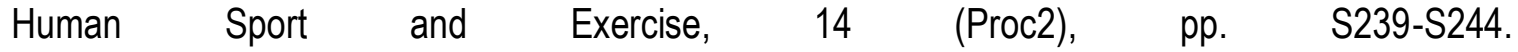
https://doi.org/10.14198/ihse.2019.14.proc2.12

Swindell, R., Thompson, J., (1995) An International Perspective of the University of the Third Age. Beckett, Francis. The U3A Story. Fran Admin.

Tiziana, D., Antonetta, M., Gaetano, A. (2017) Health and physical activity, Sport Science, 10 (1), pp. 100-105.

Tore, A.D., Altavilla, G., D'Isanto, T. (2018) Situation awareness in sports science: Beyond the cognitive paradigm, Sport Science, 11 (1), pp. 25-28.

Valentini, M., Riccardi, F., Raiola, G., Federici, A. (2018a) Educational research: Motor area and relational area during children's personality development, Journal of Physical Education and Sport, 18, art. no. 327, pp. 2157-2174.

Valentini, M., Bernardini, C., Beretta, A., Raiola, G. (2018b) Movement and language development as an early childhood twin strategy: A systematic review, Sport Mont, 16 (3), pp. 107-112. https://doi.org/10.26773/smj.181019 